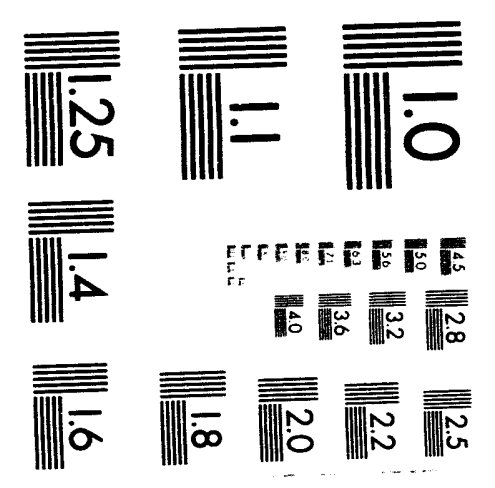




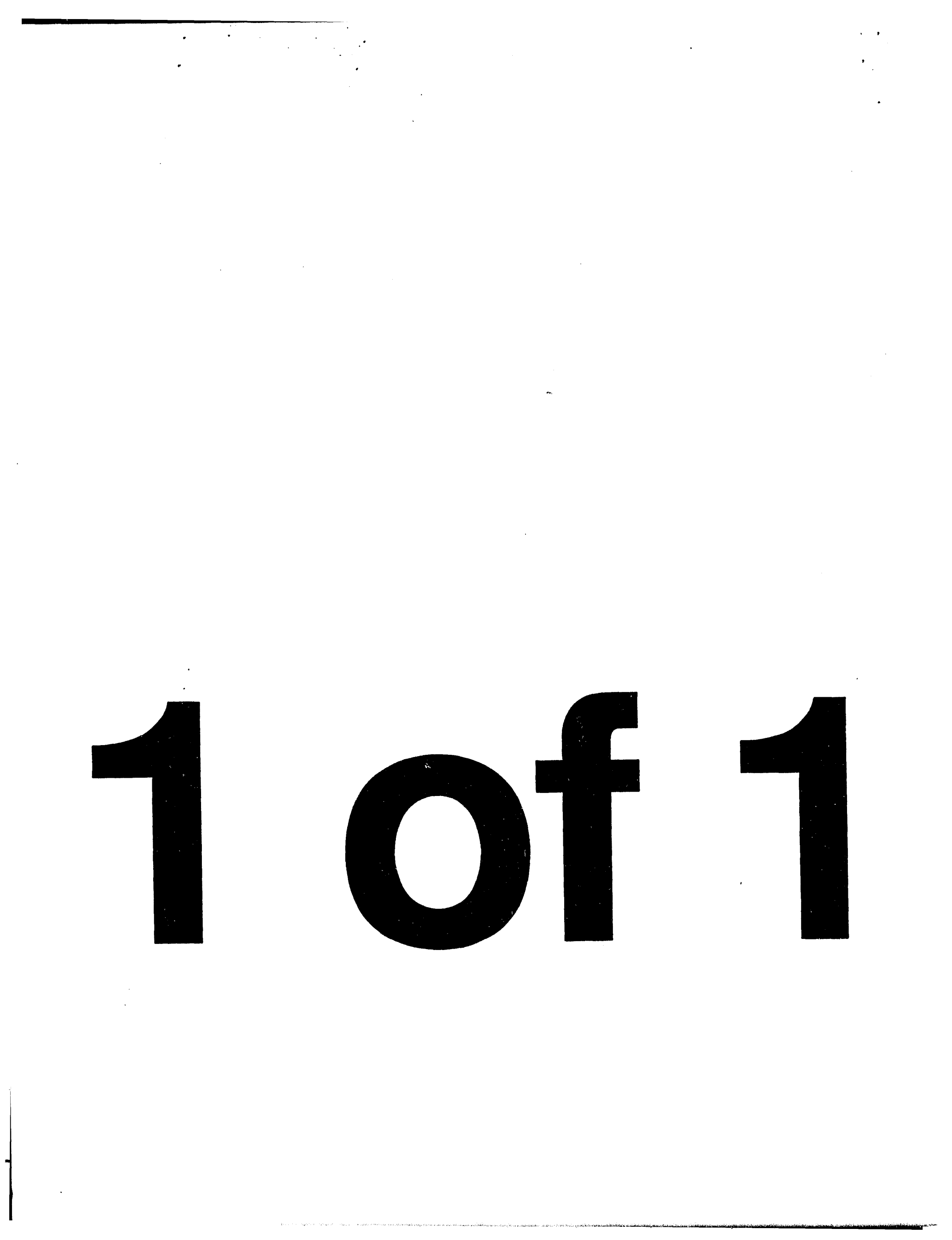




\section{Conf-940407--3}

WHC-SA-2254-FP

\section{Thermal-Spectrum Recriticality Energetics}

Prepared for the U.S. Department of Energy Office of Environmental Restoration and Waste Management

\section{We Westinghouse \\ W Hanford Company Richland, Washington}

Hanford Operations and Engineering Contractor for the

U.S. Department of Energy under Contract DE-AC06-87RL10930

列 Copyright License By acceptanco of this andide, the publisher and in this paper. 


\title{
Thermal-Spectrum Recriticality Energetics
}

\author{
K. N. Schwinkendorf
}

Date Published

December 1993

To Be Presented at

Reactor Physics Faces

the 21st Centuly

Knoxville, Tennessee

April 11-15, 1994

To be Published in

Proceedings

Prepared for the U.S. Department of Energy

Office of Environmental Restoration and

Waste Management

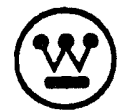

Westinghouse

P.O. Box 1970

Hanford Company Richland, Washington 99352

Hanford Operations and Engineering Contractor for the

U. Department of Energy under Contract DE-AC06-87RL10930

Copyright Lleense By accoptanco of this articlo, the publisher and/or rocipiont acknowlodges the U.S. Government's right to

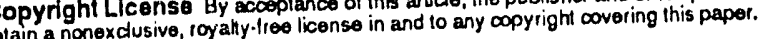




\section{LEGAL DISCLAIMEA}

This report was prepared as an account of work sponsored by an agency of the United States Government. Neither the United States Government nor any agency thereot, nor any of their employees, nor any of their contractors, subcontractors or their employees, makes any warranty, express or implied, or assumes any legal liability or responsibility lor the accuracy, completeness, or any third parly's use or the results of such use of any information, apparatus, product, or process disclosed, or represents that its use would not infringe privately owned rights. Reference herein to any specilic commercial product, process, or service by trade name. trademark, manulaclurer, or otherwise, does not necessarily constitute or imply its endorsement, recommendation, or favoring by the United States Government or any agency thereof or its contractors or subcontractors. The views and opinions of authors expressed herein do not necessarily slate or reflect those of the Uniled States Government or any agency thereot.

This report has been reproduced from the best available copy.

Printed in the Unitod Stales of America

DISCLM-2.CHP (1-91) 
K. N. Schwinkendorf

\author{
Westinghouse Hanford Company \\ Engineered Applications \\ P. O. Box 1970 \\ Richland, Washington 99352 USA \\ 1 (509) 376-0960
}

KEYWORDS: recriticality, thermal, transient

\begin{abstract}
Large computer codes have been created in the past to predict the energy release in hypothetical core disruptive accidents (CDA), postulated to occur in liquid metal reactors (LMR). These codes, such as SIMMER, are highly specific to LMR designs. More recent attention has focused on thermal-spectrum criticality accidents, such as for fuel storage basins and waste tanks containing fissile material. This paper presents results from recent one-dimensional kinetics simulations, performed for a recriticality accident in a thermal spectrum. Reactivity insertion rates generally are smaller than in LMR CDAs, and the energetics generally are more benign. Parametric variation of input was performed, including reactivity insertion and initial temperature.

\section{INTRODUCTION}

Best-estimate accident simulation is a mature field as related to liquid metal reactors (LMR). Large computer codes have been written, such as the VENUS and $S_{N}$ Implicit, Multifield, Multicomponent, Eulerian Recriticality' (SIMMER) codes. These codes simulate the coupled multigroup neutronics, with liquid sodium fluid dynamic feedback. SIMMER in particular treats multiple thermal hydraulic channels, and tracks material component redisiribution as the simulated transient progresses. However, there are numerous accident scenarios that can be postulated that occur in thermal neutron systems. These include well-moderated ex-reactor criticality accidents, accumulation of fissile material into a critical configuration inside a waste tank, and water reflood of a damaged light water reactor (LWR) core (such as Three-Mile Island) with water that is insufficiently borated.

Previous recriticality energetics analyses dealing with the conversion of the WNP-1 reactor to a tritium production facility, revealed a lack of sophisticated simulation tools for LWRs, or thermal-spectrum systems in general. It was found that although detailed core melt simulations had been performed in connection with loss of coolant accident (LOCA) events for LWRs, these scenarios were based on decay heat acting as the thermal source, rather than on fission power (i.e., there was no coupled simulation code available that modeled transient neutronics with fluid
\end{abstract}


dynamics and material redistribution in the $\therefore$ ay SIMM:ER does for a fast-spectrum system.) Other hypothetical criticality events investigated a: the Henford Site have included criticality in a waste tank. These tanks are large enough, ard contain sufficient fissile material (albeit at a highly subcritical average concentration), that a critcality could occur, given some kind of concentrating mechanism (e.g., preferential precipitation). It is thought that in such an event, the reactivity insertion rate at critical would be low encigh so that the resulting neutronic transient would be influenced strongly by the evolving thermal currents, thus shutting down the event by fissile material dispersal; fluid flow feedback vauld likely disperse the critical configuration before enough time elapsed to attain prompt critical.

This paper presents results for a ty fical space-time accident simulation. This simulation models an accumulation of fissile material debris into a cylinder of fixed radius. This scenario would be the expected result of a reactor LOCA event, with mollen fuel relocating at the bottom of the core inside a cylindrical support structure, such as the type employed in heavy-water production reactors. The one space dimer.sion modeled was the radial dimension of the cylinder, which will be referred to from now on as the 'fuel core', or 'core'. The surrounding material is modeled as heavy water. The cylinder he aht dimensions are modeled as perpendicular buckling leakage corrections to the group-dependert absorption cross sections in the core and heavywater-reflector regions. Once the steacy state is found (by adjusting the core height), the neutronic transient is driven by a time-cependent axial buckling function. As the neutronic transient evolves, a transient, radial-heat-iransfer calculation (driven by the rarial-heat-source density supplied by local fission power) concurrently updates the temperature in each radial mesh interval. The macroscopic cross-section library accessed by the neutronics is tabulated as a function of temperature, and is interpolated each time step to update local cross sections (on a mesh-by-mesh basis); both thermal and neutronic profiles are mutually coupled. Although Doppler feedback (built into the cross sections) mitigates the transient and causes power peaks, power will continue to rise because more and more molten material continues to accumulate on top (i.e., reactivity insertion continues). The ultimate shutdown mechanism is the melt-through of the cylinder support structure, with subsequent gravity collapse of the fuel column.

\section{DETAILS OF ANALYSIS}

The computer code written to perform this simulation, ATHENA, is a one-dimensional, space-time neutron diffusion kinetics code that treats two neutron energy groups, fast and thermal. The spatial dimension is cylindrical; and reactivity is inserted by specifying the fuel debris mass accumulation rate, which causes a linear increase in core height with time. The transient, two-group neutron diffusion equations in cylindrical geometry are

$$
\begin{aligned}
& \frac{1}{V_{1}} \frac{\partial \phi_{1}}{\partial t}-\frac{1}{r} \frac{\partial}{\partial r}\left(r D_{1} \frac{\partial \phi_{1}}{\partial r}\right)+\left(\Sigma_{r_{1}}+D_{1} B_{2}^{2}(t)\right) \phi_{1}=(1-\beta)\left(\nu \Sigma_{1_{1}} \phi_{1}+\nu \Sigma_{f_{2}} \phi_{2}\right)+\sum_{i=1}^{10} \lambda_{1} C_{1} \\
& \frac{1}{V_{2}} \frac{\partial \phi_{2}}{\partial t}-\frac{1}{r} \frac{\partial}{\partial r}\left(r D_{2} \frac{\partial \phi_{2}}{\partial r}\right)+\left(\Sigma_{z_{i}}+D_{2} B_{2}^{2}(t)\right) \phi_{2}=\Sigma_{1-2} \phi_{1} .
\end{aligned}
$$

Definitions of these terms may be found in the "List of Symbols" following the "References" section. The delayed neutron equations were extended to ten groups for heavy water, to treat photoneutron effects. The delayed neutron equations are 


$$
\frac{d C_{1}}{d t}=\beta_{1}\left(v \Sigma_{f_{1}} \phi_{1}+v \Sigma_{f_{2}} \phi_{2}\right)-\lambda_{1} C_{1} l=1, \ldots, 10
$$

The core height function is calculated as follows:

$$
H(t)=H\left(\tau_{0}\right)+\int_{\varepsilon_{0}}^{:} \frac{\dot{m}}{\rho_{f} \pi R^{2}} d \tau .
$$

This core height then is incorporated into a buckling function:

$$
B_{z}^{2}(t)=\left(\frac{\pi}{H(t)+2 \delta}\right)^{2}
$$

This function then is added, by group, to the removal cross section of each neutron equation. The macroscopic nuclear cross sections were obtained from the British WIMS-D lattice transport computer code ${ }^{2}$, using the Eritish 69-group fine group library. Cross sections were generated for a lattice cell composed of the fuel debris core, surrounded by a heavy-water moderator, for a series of temperatures up to the boiling temperature of the alloy fuel. To allow ATHENA to treat boiling, the cross sections were extended at the boiling temperature, but for reduced densities. This allowed ATHENA to interpolate cross sections as a function of reduced mixture density during boiling, if the transient progressed to that point.

A single cylinder of the type modeled would not go critical by itself: a nearly coherent melt, with hundreds of these cylinders filling with fuel debris, was predicted to go critical by MCNP ${ }^{3}$ Monte Carlo calculations. The ATHENA prediction for the critical height was forced to match the MCNP prediction for the finite array of cylinders by adjusting the outer boundary albedo. The albedo value that produced the MCNP critical height was equal to 0.993 .

Radial heat transfer within the fuel debris was driven at each radial mesh by the local fission power, determined by the two-group kinetics solution from the previous time step. The heat transfer boundary condition was convective pool boiling at the interface between the cylinder structure and the surrounding heavy-water moderator. The radial heat transfer model was

$$
p C_{p} \frac{\partial T}{\partial t}-\frac{1}{r} \frac{\partial}{\partial I}\left(I k \frac{\partial T}{\partial I}\right)=q(I, t) .
$$

\section{NUMERICAL METHODS}

Both neutron diffusion and heat transport equations were integrated in time by using finife difference approximations. The neutron diffusion equations were integrated over each mesh point to arrive at a set of coupled algebraic equations. These equations are three-point coupled in space, with another constant coupling to the 'other' group. After performing the requisite algebra, all terms containing the flux at the 'future' time are brought over to the left-hand side, while all terms containing 'present' information (i.e., time step $t_{j}$ ) are collected into the right-hand side, or 
rhs $_{\text {g,1.j. }}$. All results presented in the following section were produced using Crank-Nicolson, or semiimplicit differencing. The form of the system is

$$
\begin{aligned}
& \ell_{j} \phi_{1, i-1, j+1}+d_{i} \phi_{1, i, j+1}+u_{i} \phi_{1, i+1, j+1}+d o_{i} \phi_{2, i, j+1}=I h s_{1, i, j} \\
& \ell_{i}^{\prime} \phi_{2, i-1, j+1}+d_{i}^{\prime} \phi_{2, i, j+1}+u_{i}^{\prime} \phi_{2, i+1, j+1}+d O_{i}^{\prime} \phi_{1, i, j+1}=I h s_{2, i, j}
\end{aligned}
$$

By staggering the fast and thermal fluxes, it is possible to write this system in the form of a five-diagonal matrix, as follows:

$$
\left[\begin{array}{llllllll}
\cdots & f_{i} & 0 & d_{i} & d o_{i} & u_{i} & 0 & \ldots \\
\ldots & 0 & f_{i}^{\prime} & d o_{i}^{\prime} & d_{i}^{\prime} & 0 & u_{i}^{\prime} & \ldots
\end{array}\right]\left[\begin{array}{c}
\phi_{1, i-1} \\
\phi_{2, i-1} \\
\phi_{1, i} \\
\phi_{2, i} \\
\phi_{1, i+1} \\
\phi_{2, i+1}
\end{array}\right]_{j+1}\left[\begin{array}{c}
\cdot \\
. \\
r h s_{1, i} \\
I h s_{2, i} \\
\cdot
\end{array}\right]_{j} .
$$

Because of the stiff nature of the kinetics equations, this approach allows for a simultaneous solution of both fast and thermal equations for time step $t_{j+1}$. The neutronic time step therefore is performed using a single forward-eliminztion, backward-substitution method, optimized for a five-diagonal matrix (i.e., advantage is taken of all zeros off the five non-zero diagonals).

The radial heat transport equation was solved in a similar fashion. However, a 'slaggered mesh' was used. The neutron equations were solved for the mesh points, using finite difference equations that were generalized for different macroscopic cross sections on either side of the mesh point, but the temperature field was calculated for the mesh interval between mesh points. As the average temperature of the cell increased, this information was used to interpolate new cross sections for that interval, using a three-point Lagrangian interpolator. The neutronic equations then had new cross sections for the next time step, on either side of the mesh point. The finite difference form of the heat transport equation was collected into the more familiar tridiagonal matrix, and the temperature profile was updated using the same forward-elimination, backward-substitution method.

\section{RESULTS}

The transient was initiated, once the steady state was found, by increasing the core debris height (according to the user-input mass accumulation rate) with time. Several input parameters were varied, including fuel debris accumulation rate, initial fuel debris temperature at critical, and the temperature at which the support cylinder failed. This failure was driven by the radial-heattransfer model, which predicted the cylinder wall temperature with time. When the support structure failed, the core debris column started a downward acceleration (driven by gravity, but also retarded by buoyancy), causing neutronic shutdown of the excursion because of increased axial neutron leakage. The best estimate for the mass accumulation rate was equal to $100 \mathrm{~g} / \mathrm{sec}$, 
and the best estimate for the initial fuel cebris temperature at critical was $650 \mathrm{~K}$. The best estimate for structural failure of the support cylinder vas $908 \mathrm{~K}$.

Table 1 shows the predicted energy release as a function of mass accumulation rate, per fuel debris cylinder, for the base case conditions, where all other input parameters are assumed to be best estimate. Initial fuel debris iemperature is equal $10650 \mathrm{~K}$. The transients that are driven with higher reactivify insertion rates result in the higher yields, as expected.

Table 1. Energy Release versus Fuel Debris Accumulation Rate.

\begin{tabular}{|c|c|}
\hline$d \mathrm{~m} / \mathrm{dt}(\mathrm{g} / \mathrm{sec})$ & Energy Release $=$ Pdt $(\mathrm{MJ})$ \\
\hline 50 & 3.616 \\
\hline 70 & 3.941 \\
\hline 100 & 4.357 \\
\hline 150 & 4.962 \\
\hline 200 & 5.481 \\
\hline 300 & 6.378 \\
\hline 400 & 7.144 \\
\hline 500 & 7.861 \\
\hline
\end{tabular}

Table 2 shows the predicted energy release as a function of initial core debris temperature. The fuel debris mass accumulation rate is equal to $100 \mathrm{~g} / \mathrm{sec}$. As the starting temperature of the fuel debris increases, less energy is required before the structure fails.

Table 2. Energy Release versus Initial Fuel Debris Temperature.

\begin{tabular}{|c|c|}
\hline Initial $T_{\text {core }}(K)$ & Energy Release $=(\mathrm{Pdt}(\mathrm{MJ})$ \\
\hline 650 & 4.357 \\
\hline 700 & 3.813 \\
\hline 750 & 3.214 \\
\hline 800 & 2.587 \\
\hline 850 & 1.976 \\
\hline 875 & 1.704 \\
\hline 900 & 1.342 \\
\hline
\end{tabular}

Figure 1 illustrates a plot of average core power as a function of time, for a set of five different mass accumulation rates $(10010500 \mathrm{~g} / \mathrm{sec})$. These mass accumulation rates correspond to increasing reactivity insertion rates. 


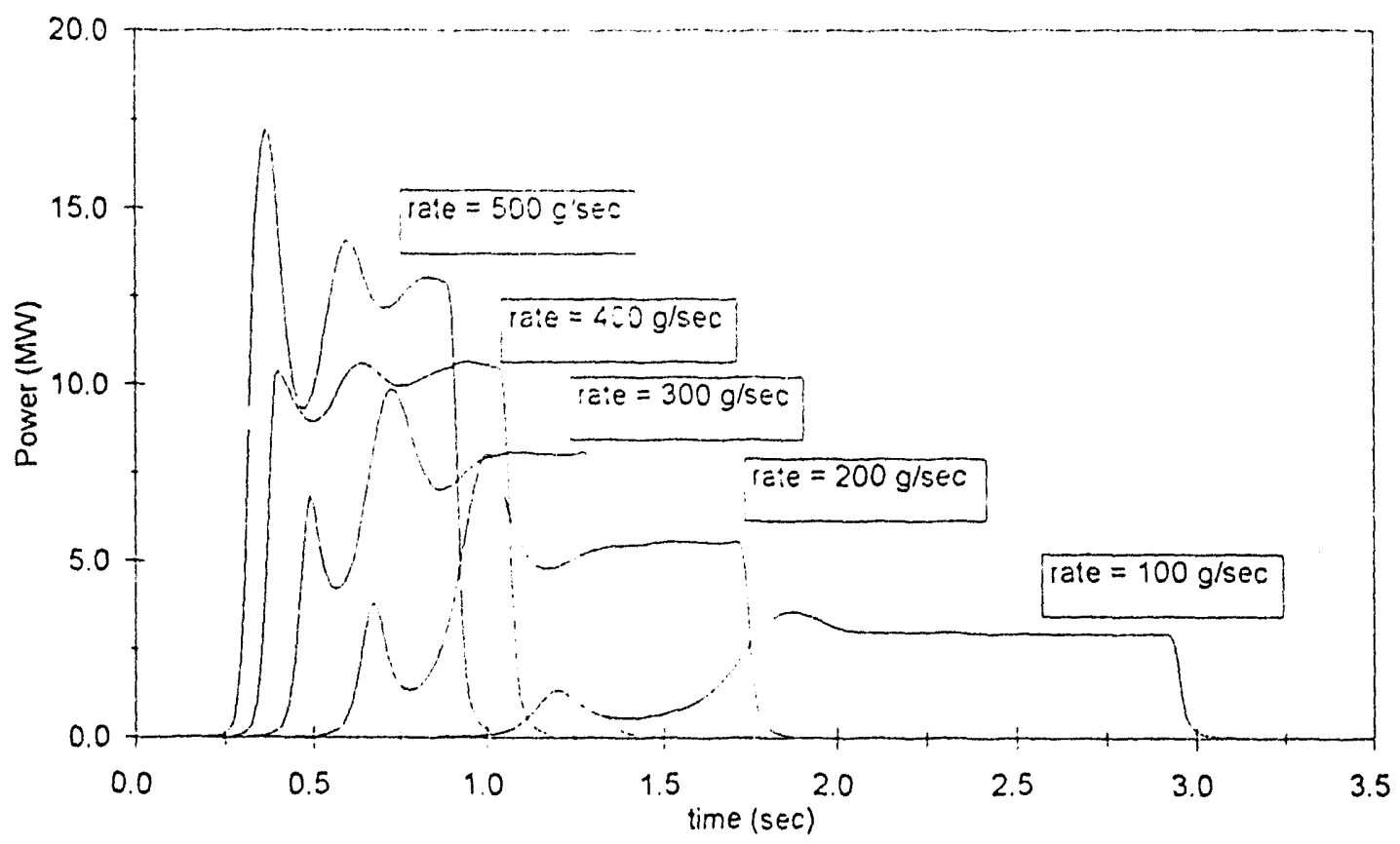

Figure 1. Average Power vs. Time.
(Comparison of Mass Addition Rate)

Figure 2 shows the variation in total energy release with increasing mass addition rate, and Figure 3 shows the variation in energy release with initial fuel debris temperature. Figure 4 shows the sensitivity of the total energy release to the assumed failure temperature of the outer support structure. If this support structure fails at a higher temperature, the transient is allowed to progress further before shutdown, and total yield is increased. In this particular problem, it was not well understood whether this failure criterion should be taken as the material's melting point, or perhaps another, slighlly lower temperature (where structural rigidity was reduced) should be assumed.

\section{FUTURE WORK}

The ATHENA code can be extended to a fully two-dimensional, multigroup simulator. The existing code, in addition to the five-diagonal matrix inverter routine, also allows the user to choose successive overrelaxation (SOR), with user-input inner iterations per outer, SOR parameters, convergence criteria, etc. The 2D $(r, z)$ ATHENA code will employ both SOR and an alternating-direction implicit (splitting) algorithm. The energy equation also is being extended to include fluid motion (computational fluid dynamics, using the SIMPLE ${ }^{4}$ algorithm). This simulator will have the capability to explicitly model the coevolving neutronic and fluid dynamic fields that characterize solution critical excursions. Applications include water-reflood reactor accidents, waste tank criticalities, and fuel storage basin criticality accidents that might occur under water. 


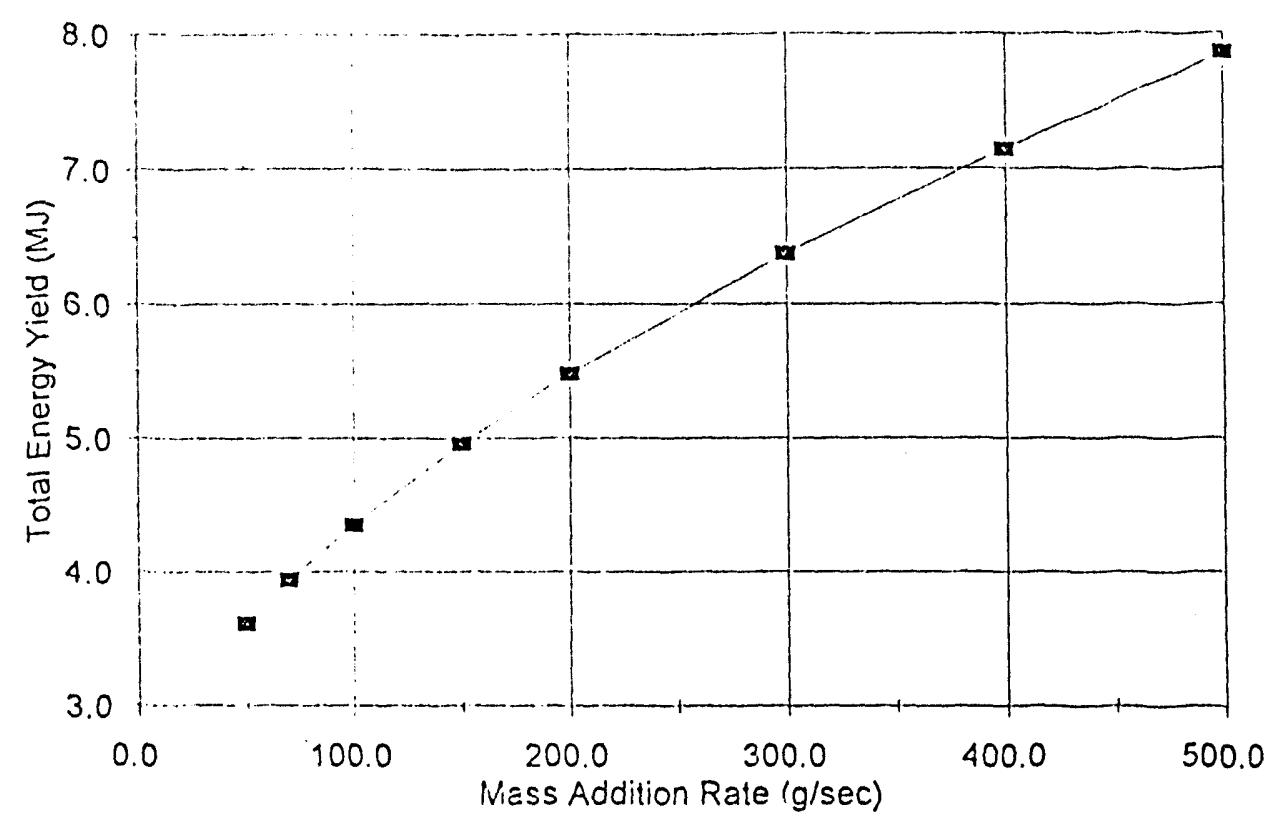

Figure 2. Yield vs. Mass Addition. (Initial Fuel Temp $=650 \mathrm{~K}$ )

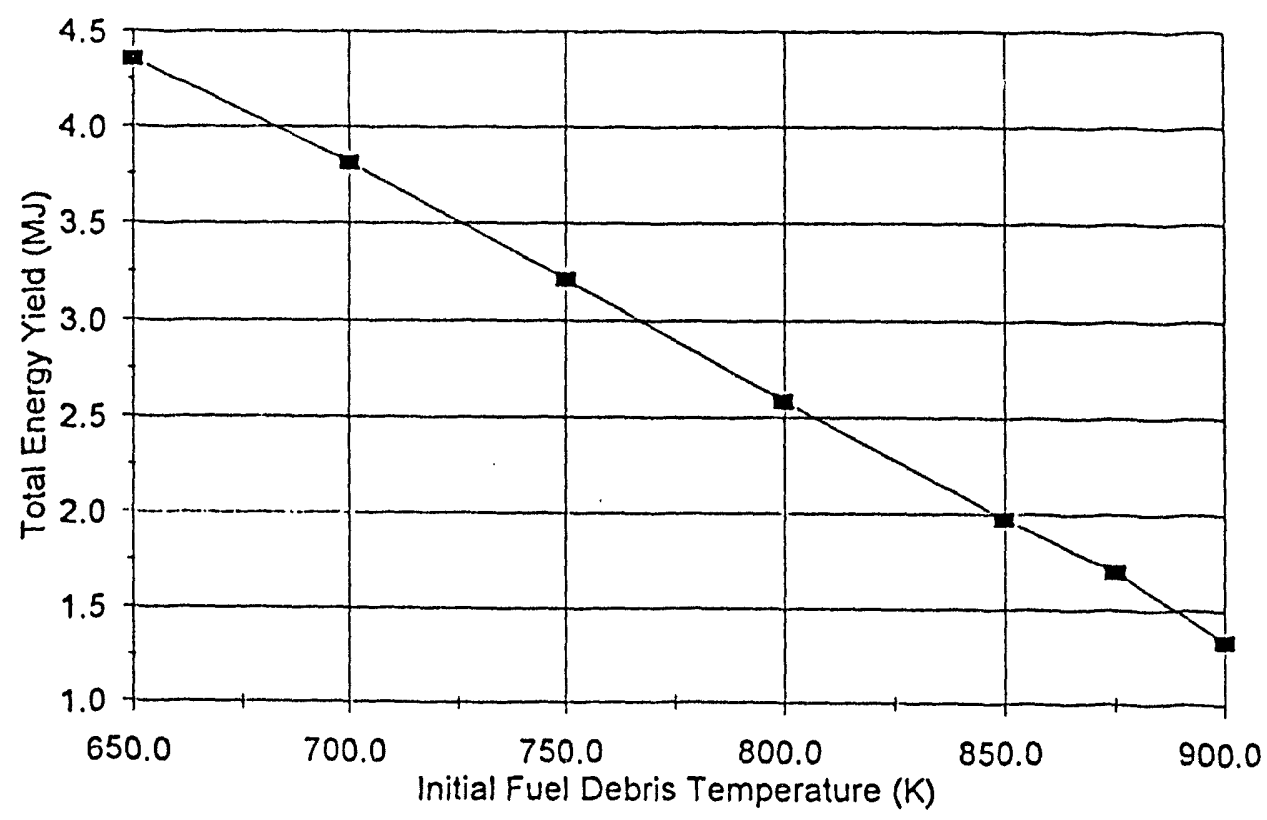

Figure 3. Yield vs. Initial Temp. (Mass Addition Rate $=100 \mathrm{~g} / \mathrm{sec}$ ) 


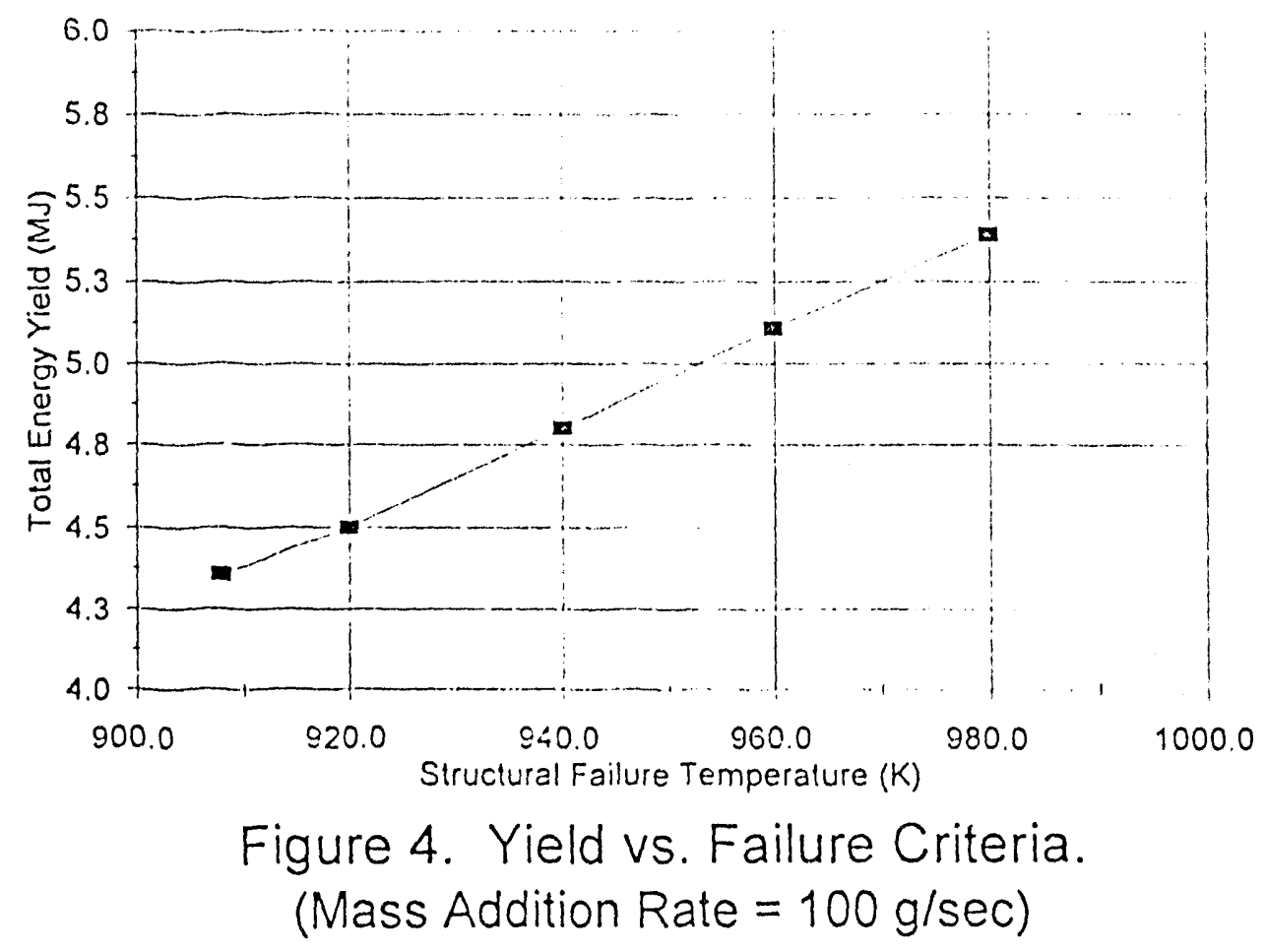

\section{CONCLUSIONS}

This paper has presented results from a coupled one-dimensional nuclear kinetics, heat transport simulation of a recriticality in a thermal system. The best estimate for the energy release from this event was on the order $4.4 \mathrm{MJ}$ per lattice unit. When one multiplies this value by the number of such units in the system $(600)$, the total yield for this hypothetical accident scenario was on the order of $2.6 \mathrm{GJ}$, which is approximately a factor of twenty less than the previously reported $60 \mathrm{GJ}$. This earlier result was based on far cruder assumptions.

\section{REFERENCES}

1. A. E. WALTAR, A. B. REYNOLDS, Fast Breeder Reactors, Pergamon Press, New York (1981).

2. M. J. ROTH, J. D. MACDOUGALL, P. B. KEMSHELL, "The Preparation of Input Data for WIMS," AEEW-R 538, General Reactor Physics Division, Atomic Energy Establishment, Winfrith, England, (1967).

3. J. A. BREISMEISTER, Ed., "MCNP - A General Monte Carlo Code for Neutron and Photon Transport, Version 3A," LA-7396-M, Rev 2, Los Alamos National Laboratory, New Mexico, (1986).

4. S. V. PATANKAR, Numerical Heat Transfer and Fluid Flow, Hemisphere Publishing Corporation, New York (1980).

5. W. SWEET, "Severe Accident Scenarios at Issue in DOE Plan to Restart Reactor," Physics Today, 44, (November 1991), pp 78-81. 


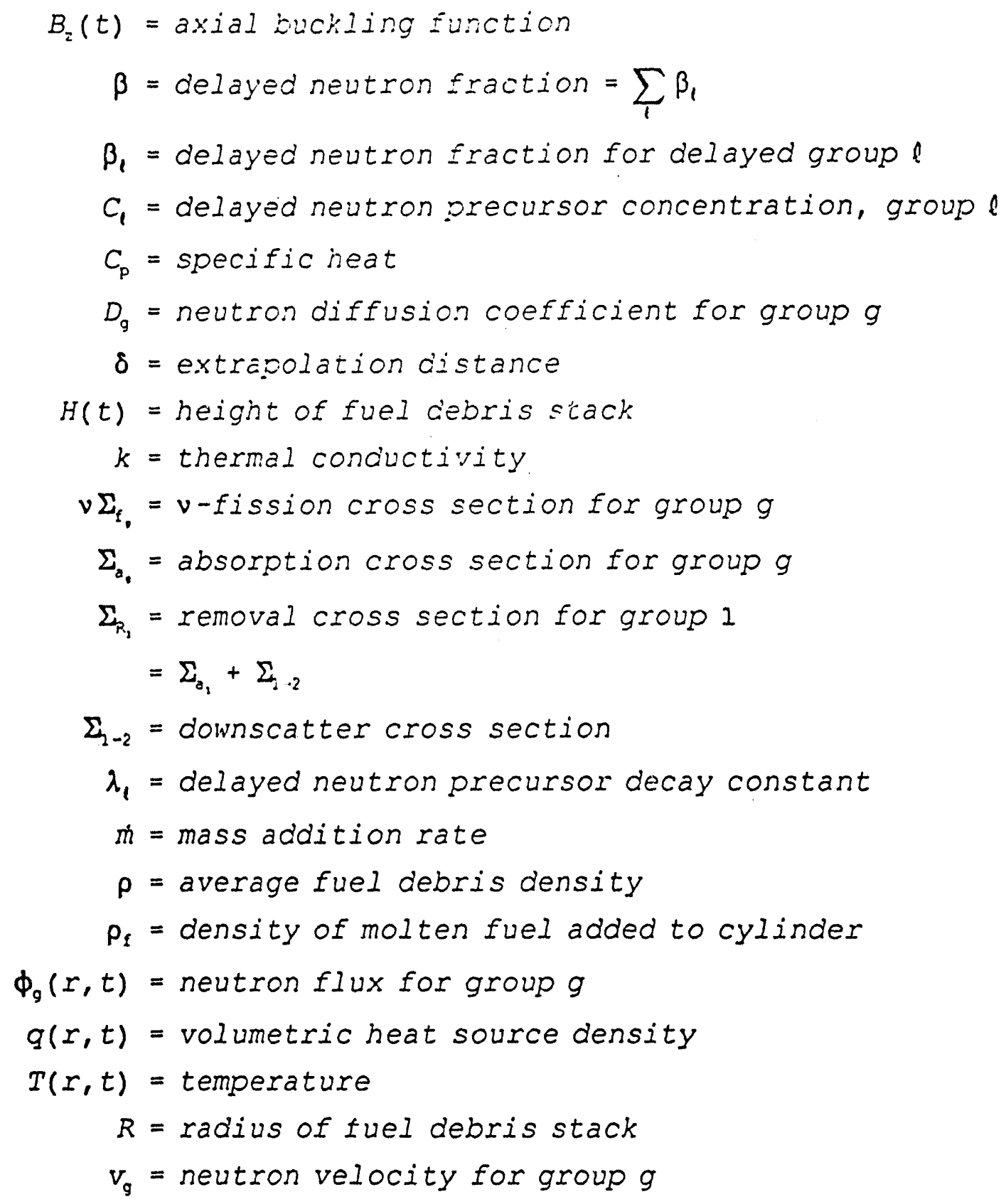




\section{DISTRIBUTION}

Number of copies

ONSITE

1

U.S. Department of Energy. Richland Operations office

R. F. Christensen

R3-72

6

Westinghouse Hanford Company

K. N. Schwinkendorf

HO-38

Information Release

Administration (3)

Publication Services

ᄂ8-07

A2-25

Distr-1 

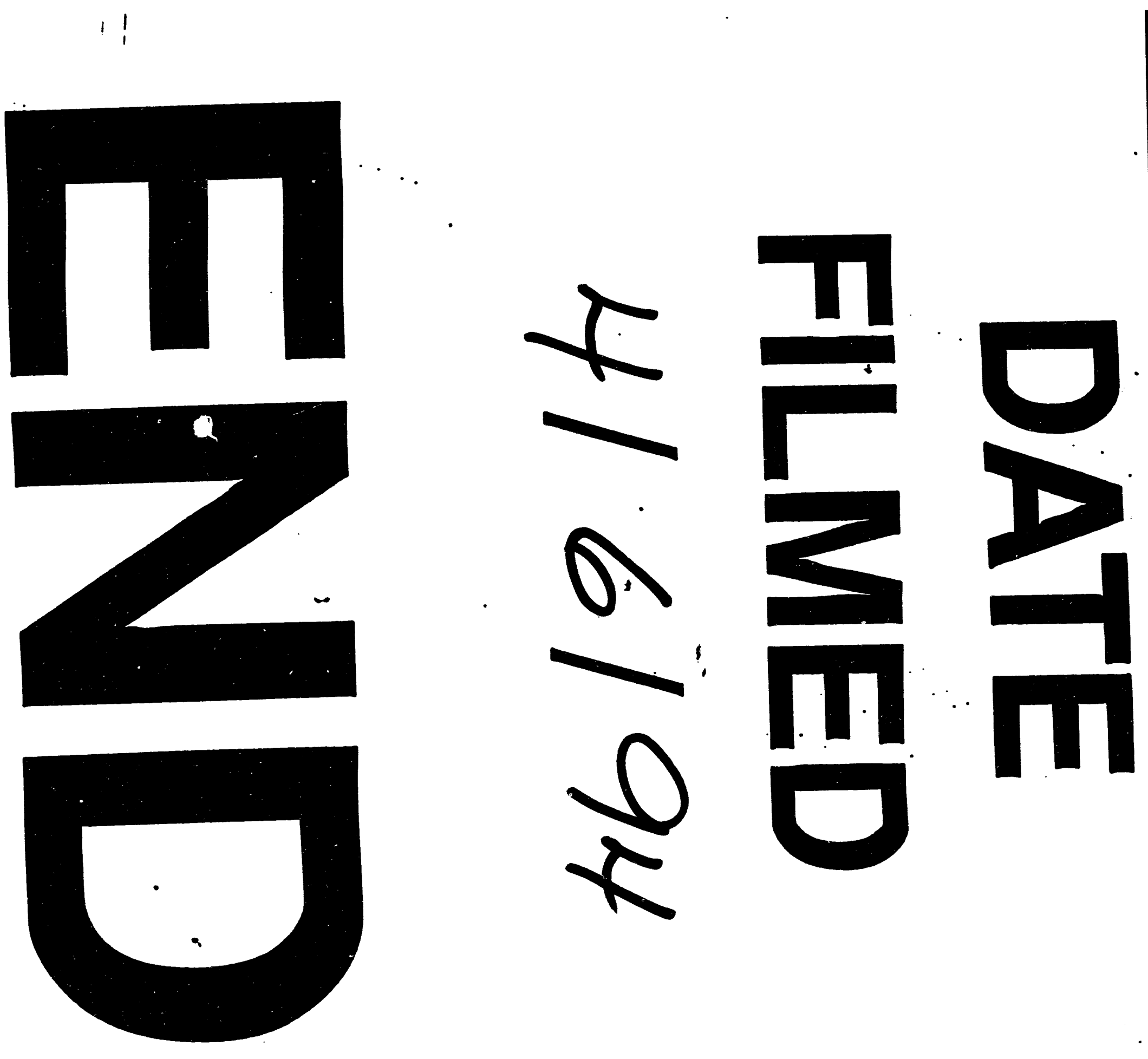


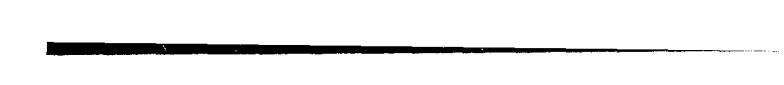

